\title{
Diorganyl Dichalcogenides as Surface Capping Ligands for Germanium Nanocrystals
}

Kathryn A. Newton, ${ }^{\dagger}$ Zheng Ju, ${ }^{\dagger}$ Katayoon Tabatabaei, ${ }^{\dagger}$ and Susan M. Kauzlarich ${ }^{\dagger},{ }^{*}$

Department of Chemistry, One Shields Avenue, University of California, Davis, CA 95616

*smkauzlarich@ucdavis.edu

\section{SUPPORTING INFORMATION}

(A)

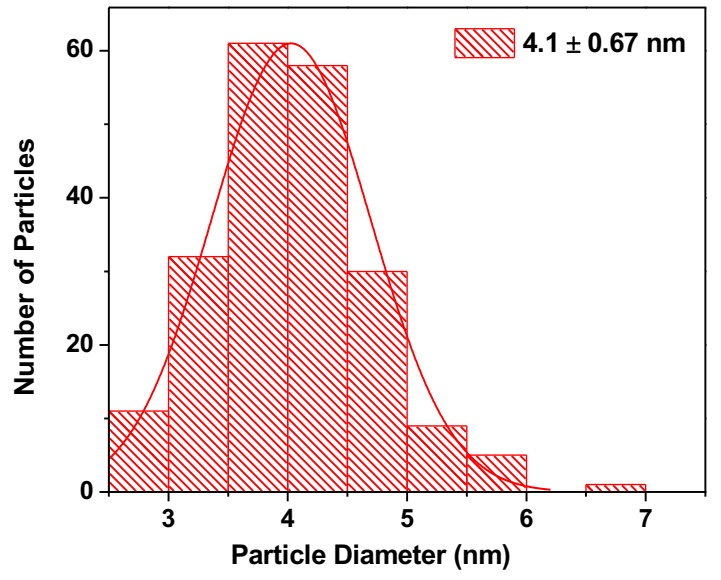

(B)

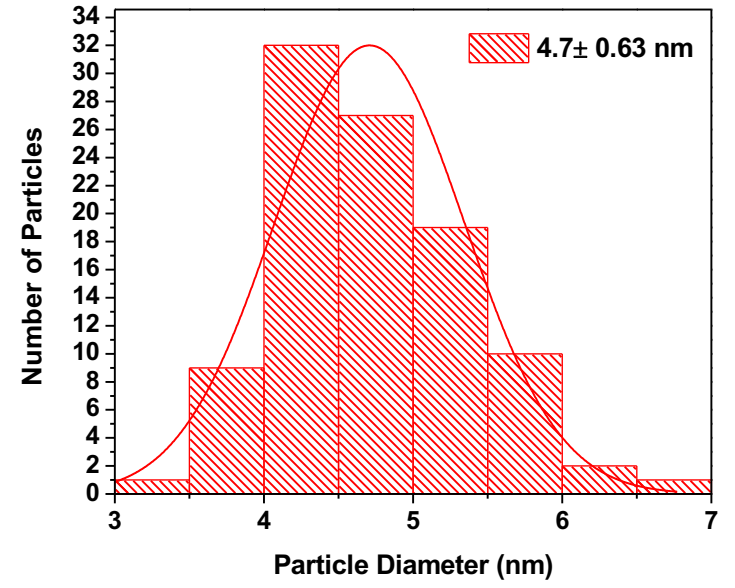

Figure S1. Particle size distribution histograms of OAm-capped Ge NCs synthesized at (A) 230 ${ }^{\circ} \mathrm{C}$ and (B) $250{ }^{\circ} \mathrm{C}$. 

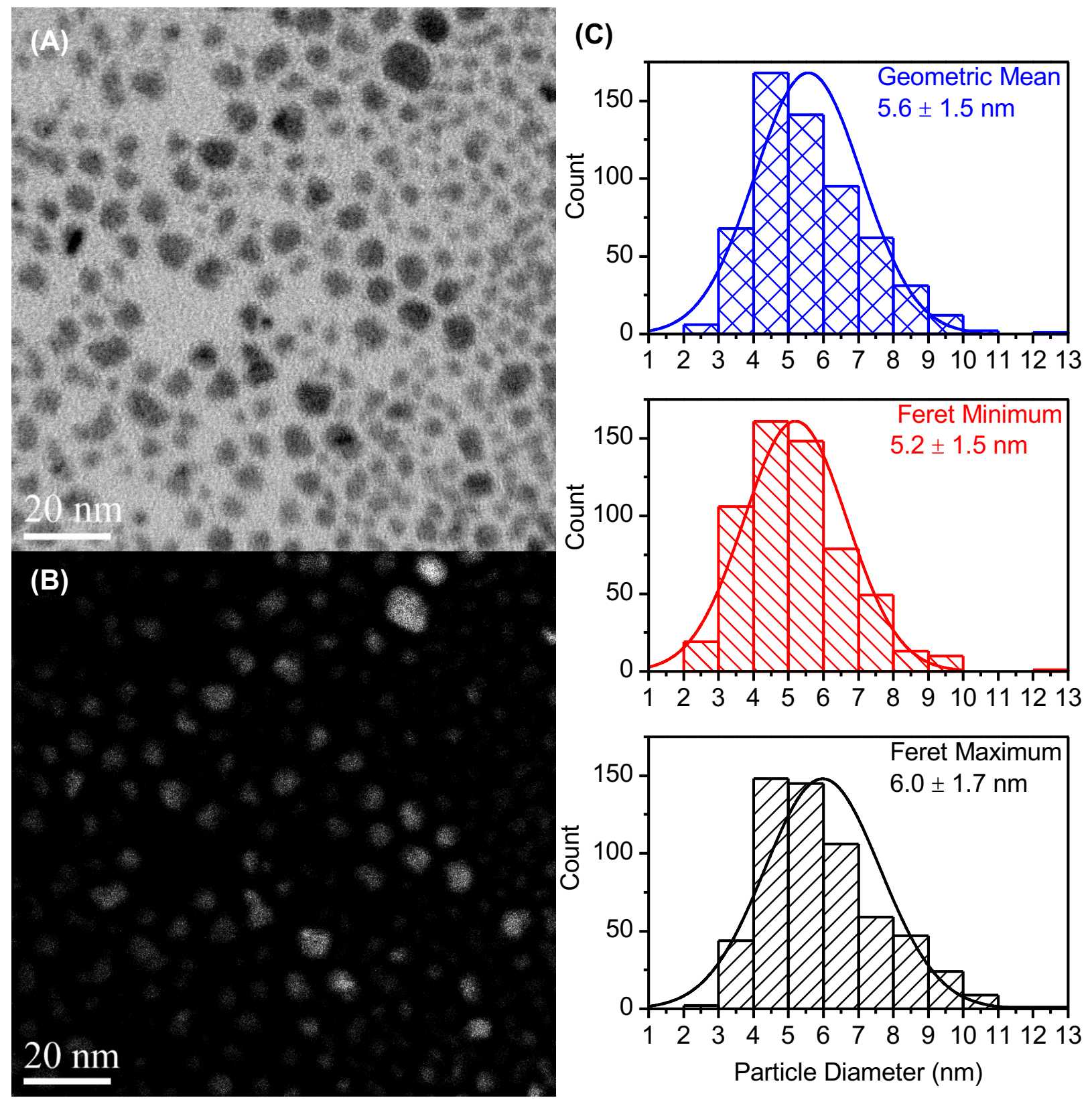

Figure S2. (A) Bright field and (B) High Angle Annular Dark Field (HAADF) STEM images of OAm-capped Ge NCs synthesized at $250{ }^{\circ} \mathrm{C}$ and (C) corresponding particle size distribution histograms. 


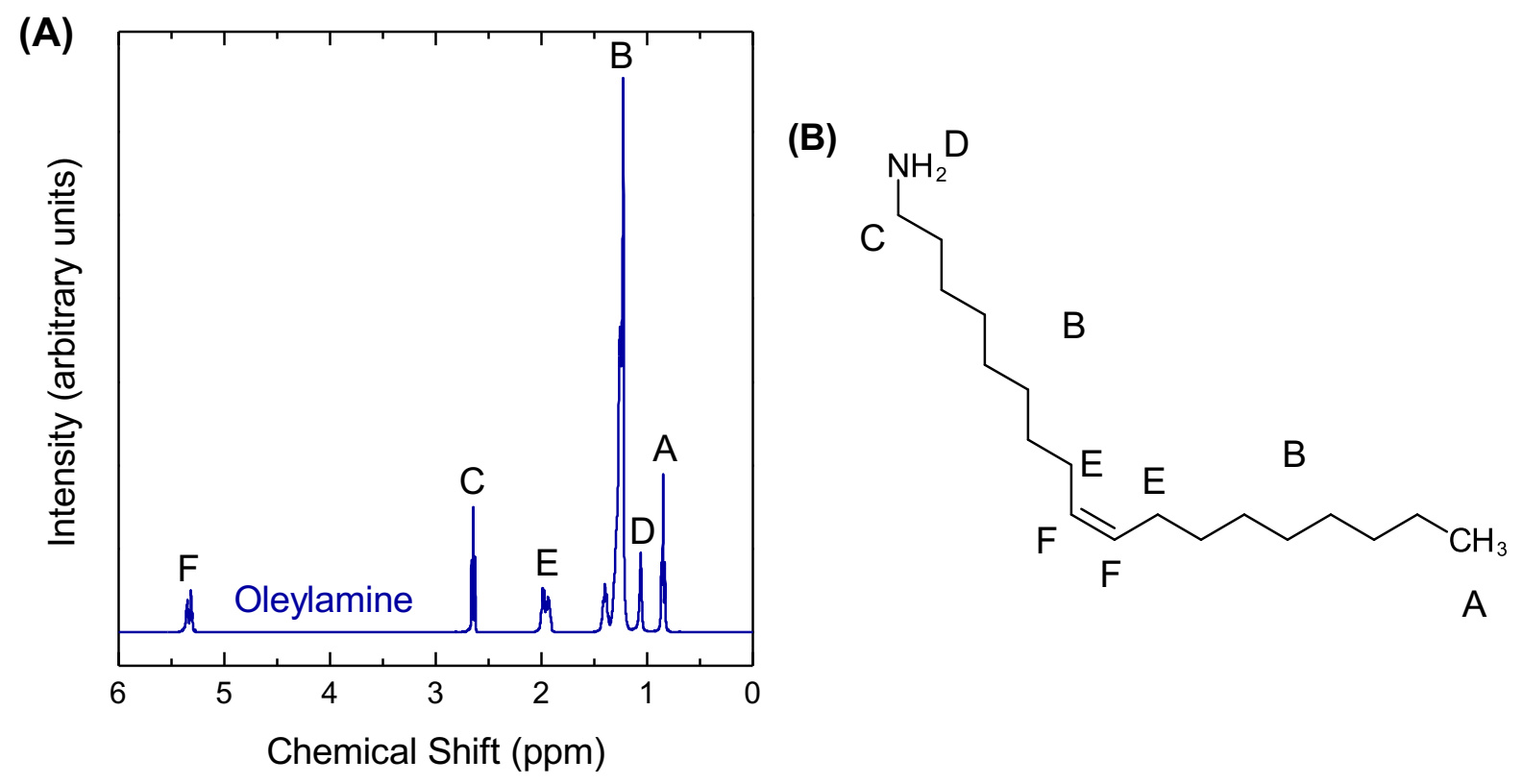

Figure S3. ${ }^{1} \mathrm{H}$ NMR spectrum of free oleylamine (OAm) and (B) the line structure of OAm with corresponding labels.

Table S1. ${ }^{1} \mathrm{H}$ NMR Chemical Shifts of Unbound Oleylamine*

\begin{tabular}{|c|c|c|}
\hline $\begin{array}{c}\text { OAm } \\
\text { Peak }\end{array}$ & $\begin{array}{c}\text { Chemical Shift } \\
\text { (ppm) }\end{array}$ & Expected Integration \\
\hline F & 5.31 & 2 \\
\hline C & 2.65 & 2 \\
\hline E & 1.98 & 4 \\
\hline B & 1.23 & 24 \\
\hline D & 1.05 & 2 \\
\hline A & 0.85 & 3 \\
\hline Total & & 37 \\
\hline
\end{tabular}

* Peak labels correspond to those in Figure S3. 
(A)

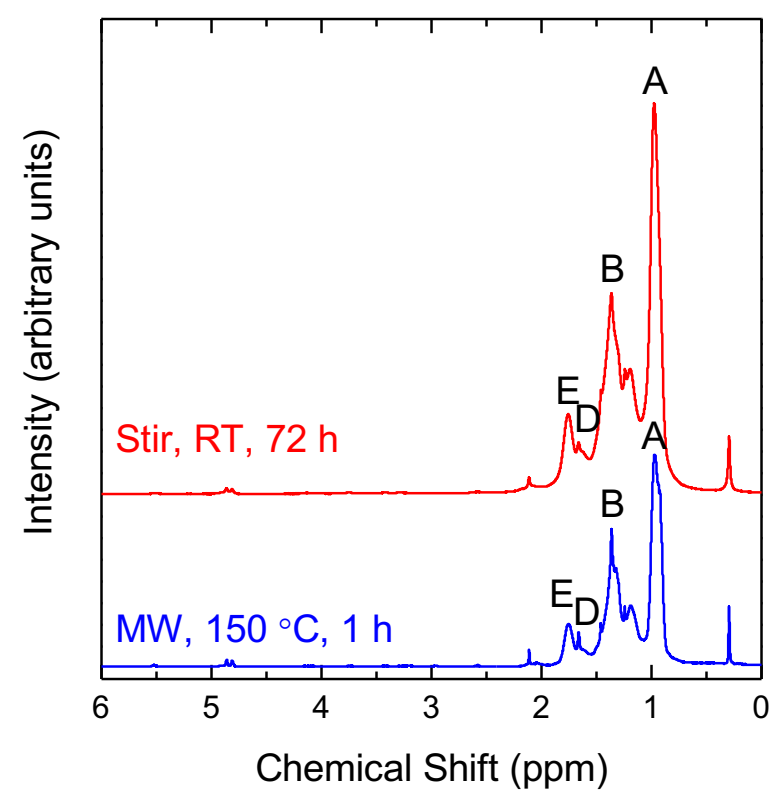

(B)

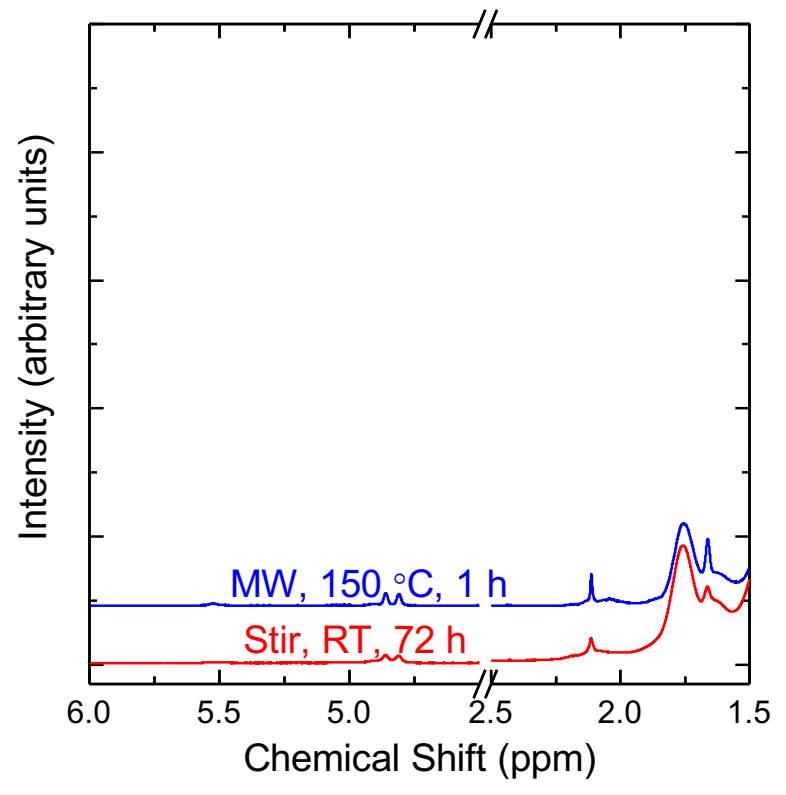

Figure S4. The ${ }^{1} \mathrm{H}$ NMR spectra of Ge NCs recapped with dioctadecyl disulfide by hydrazineassisted ligand exchange procedure with microwave-assisted heating at $150^{\circ} \mathrm{C}$ for $1 \mathrm{~h}$ or stirring at room temperature for $72 \mathrm{~h}$ shown over (A) the full range and (B) a reduced range. Peak labels correspond to those in Table S2. 


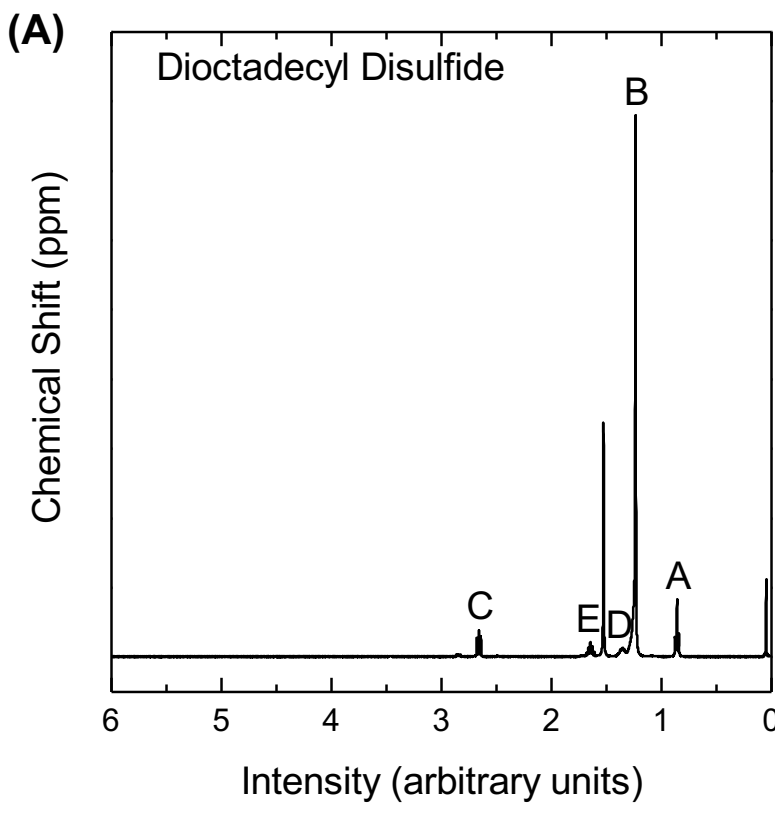

(B)

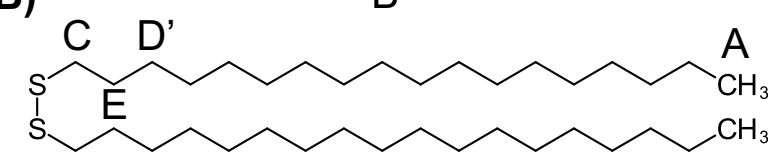<smiles>B1CCCCC1</smiles>

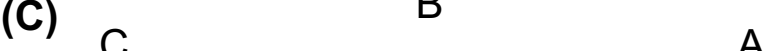
D<smiles>[B]CC(C)CCCCCCCCCCCCCCCCCCC</smiles>

Figure S5. ${ }^{1} \mathrm{H}$ NMR spectrum of dioctadecyl disulfide (DODS) and the line structures of (B) dioctadecyl disulfide and (C) 1-octadecanethiol with corresponding labels. The peak near 1.53 ppm is attributed to water impurities in the NMR solvent.

Table S2. ${ }^{1} \mathrm{H}$ NMR Chemical Shifts of Dioctadecyl Disulfide and 1-Octadecanthiol*

\begin{tabular}{|c|c|c|c|}
\hline DODS & Chemical Shift & \multicolumn{2}{|c|}{ Expected Integration } \\
\cline { 3 - 4 } Peak & (ppm) & Dioctadecyl Disulfide & 1-octadecanethiol \\
\hline C & 2.66 & 4 & 2 \\
\hline E & 1.65 & 4 & 2 \\
\hline D' & 1.36 & 4 & 0 \\
\hline D & 1.31 & 0 & 1 \\
\hline B & 1.23 & 56 & 3 \\
\hline A & 0.86 & 6 & 38 \\
\hline Total & & 74 & 3 \\
\hline
\end{tabular}

* Peak labels correspond to those in Figure 5 and SI, Figures S4-S7. 
(A)

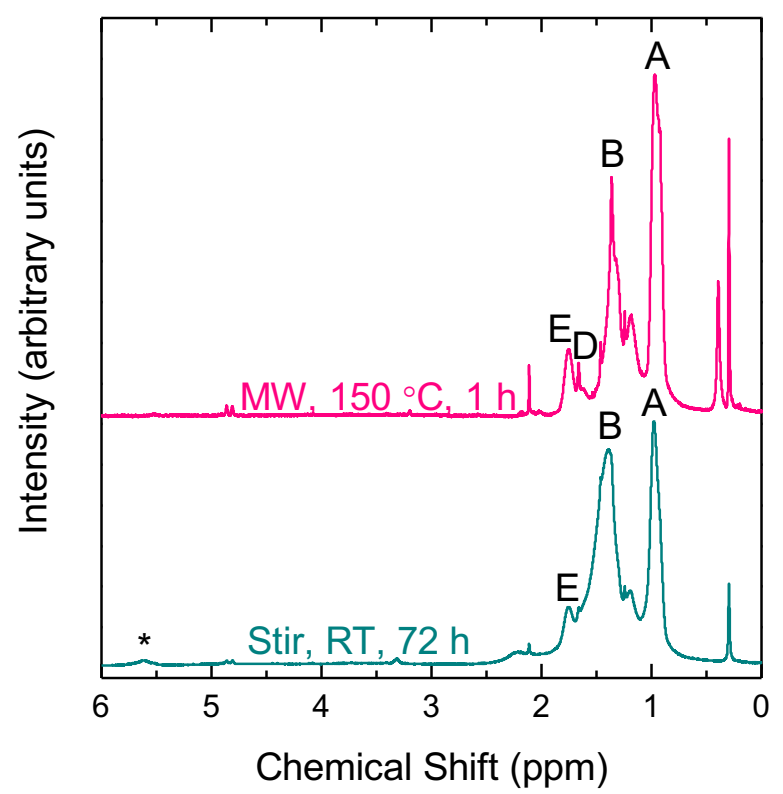

(B)

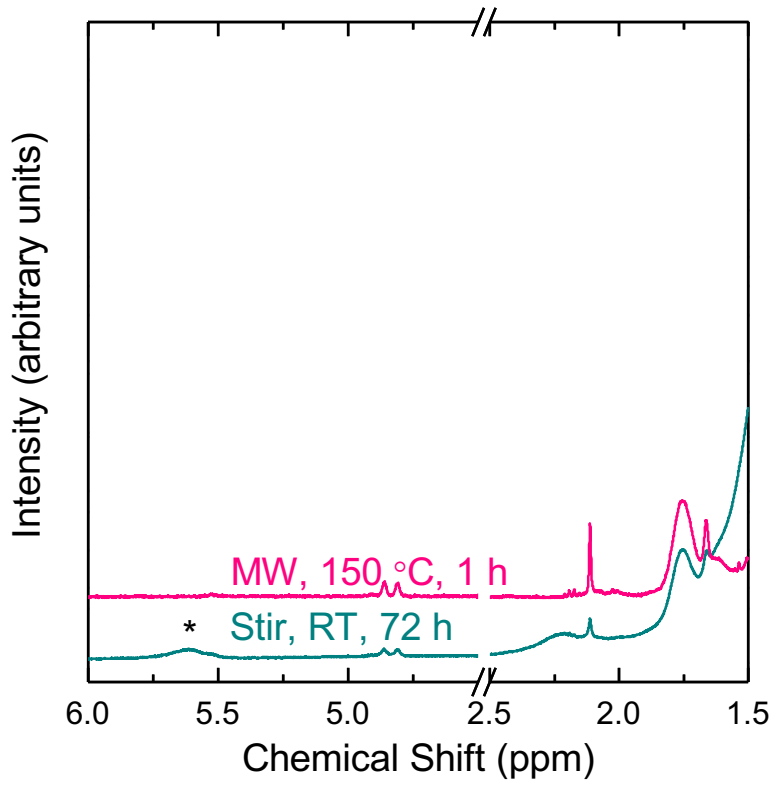

Figure S6. ${ }^{1} \mathrm{H}$ NMR spectra of Ge NCs recapped with dioctadecyl disulfide by a direct ligand exchange procedure with microwave-assisted heating at $150{ }^{\circ} \mathrm{C}$ for $1 \mathrm{~h}$ or stirring at room temperature for $72 \mathrm{~h}$ shown over (A) the full range and (B) a reduced range. Peak labels correspond to those in Table S1.

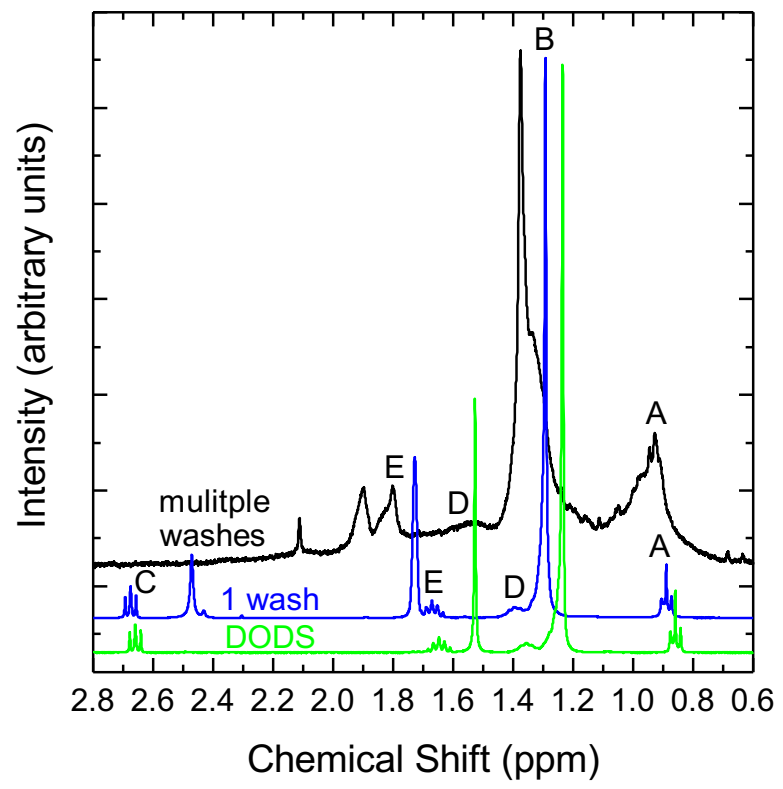

Figure S7. ${ }^{1} \mathrm{H}$ NMR spectrum of Ge NCs recapped with dioctadecyl disulfide and without $\mathrm{Ph}_{2} \mathrm{PH}$ by microwave-assisted heating at $150^{\circ} \mathrm{C}$ for $1 \mathrm{~h}$ after 1 washing step and after multiple washing steps compared to the spectrum of free dioctadecyl disulfide. Peak labels correspond to those in Table S2. 

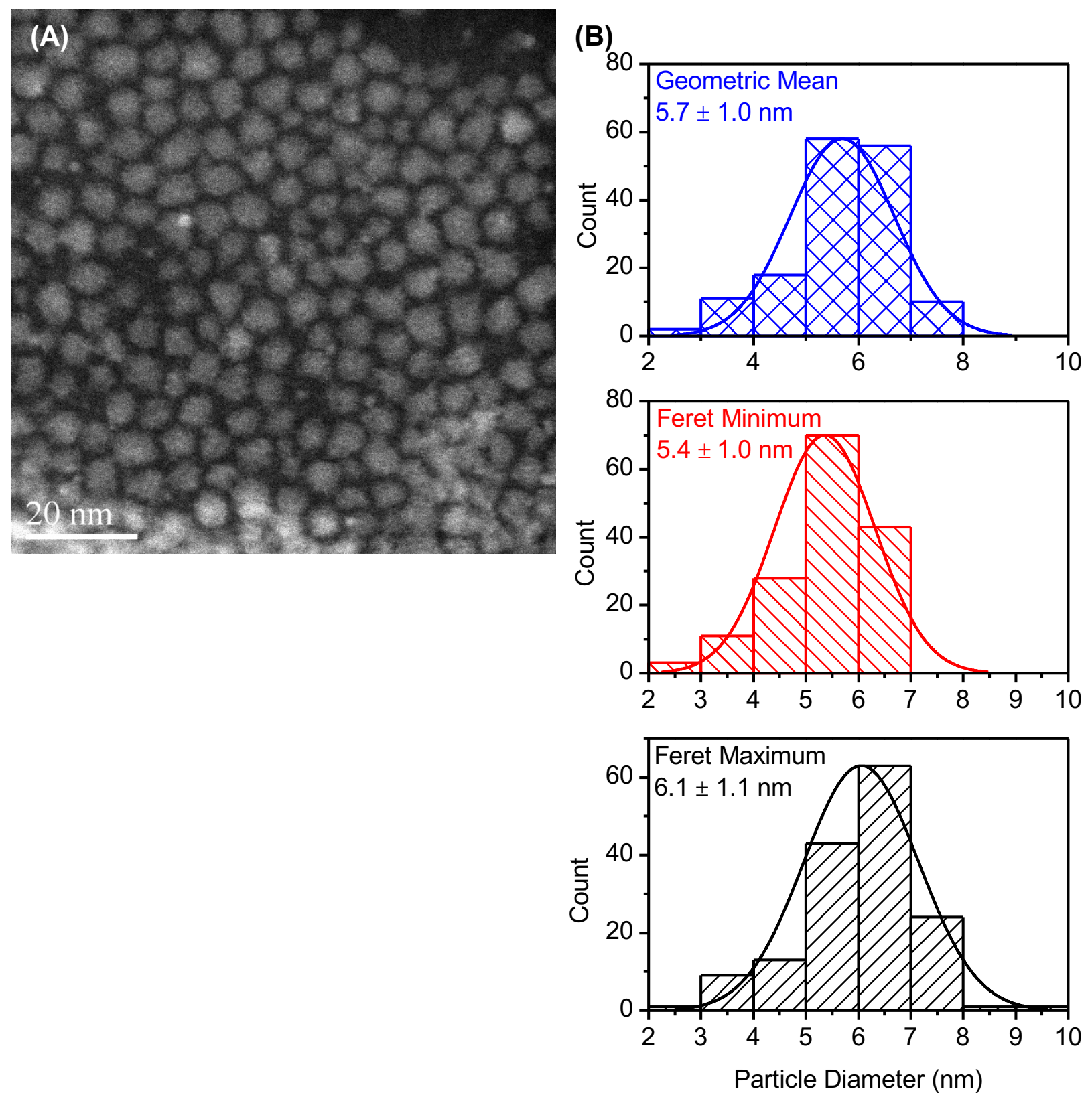

Figure S8. (A) High Angle Annular Dark Field (HAADF) STEM images of Ge NCs synthesized with dioctadecyl disulfide in the reaction mixture and $(\mathrm{C})$ corresponding particle size distribution histograms. 


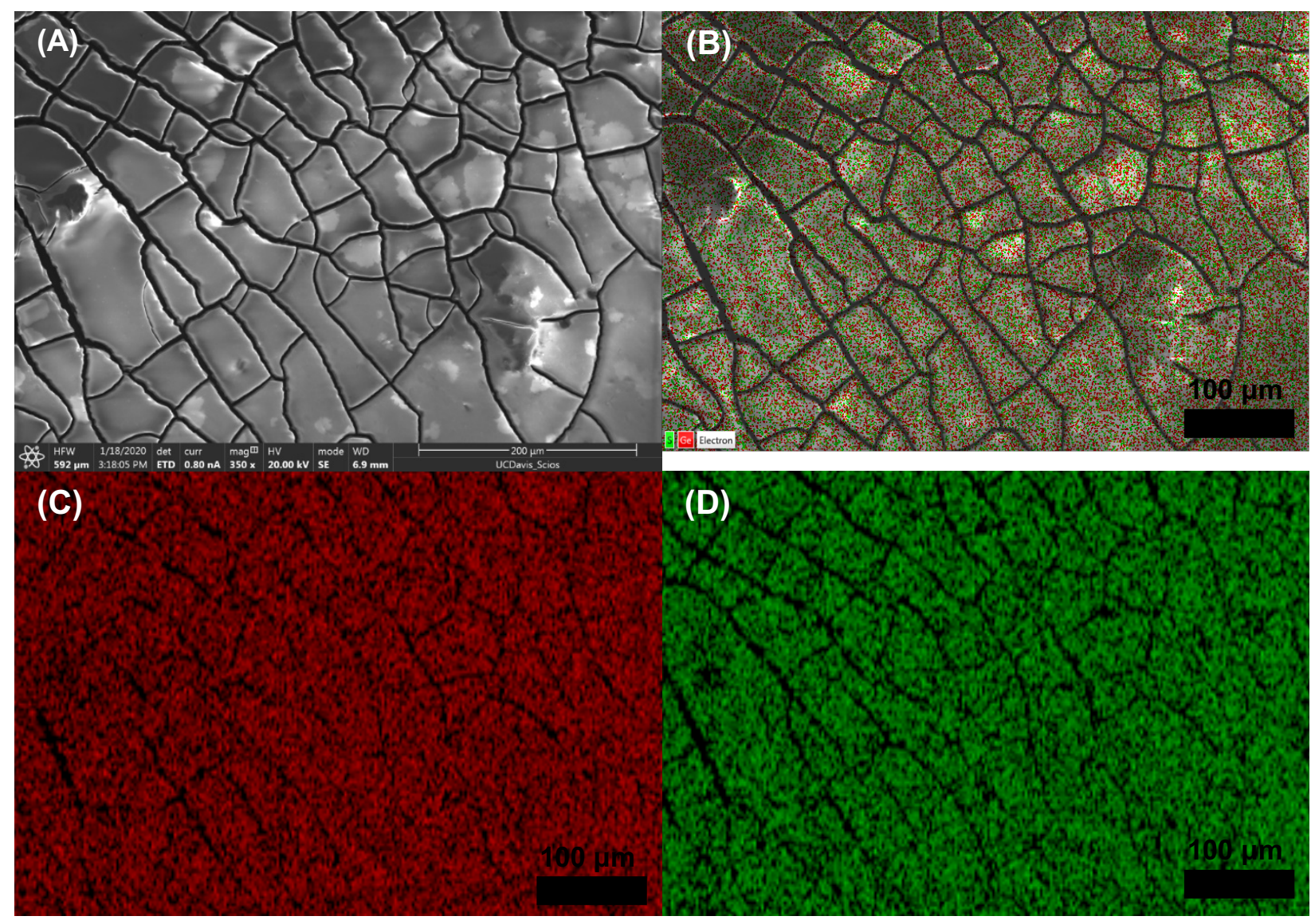

(E)

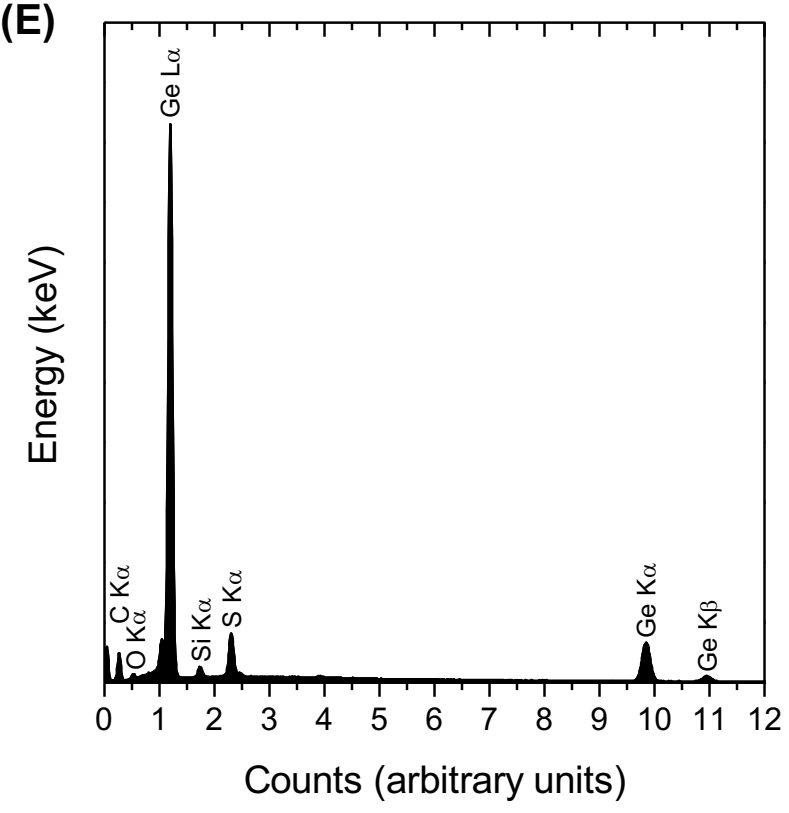

Figure S9. (A) SEM image of Ge NCs synthesized with dioctadecyl disulfide in the reaction mixture. (B) SEM image overlaid with elemental mapping of (C) Ge (red) and (D) S (green). (E) EDS spectrum collected from the map area. 